\title{
Opioid Ligand Binding to Opioid Receptors: Insight and Implications for Peptide Design
}

\author{
Michael J. Ferracane and Jane V. Aldrich \\ Department of Medicinal Chemistry, University of Florida, Gainesville, FL, 32610, USA
}

\section{Introduction}

The three opioid receptors $(\mu, \delta$, and $\kappa)$ are important targets for pain management and have also shown promise as targets for treatment of addiction and mood disorders. In the past, research in the field commonly focused on analysis of structure-activity relationships (SAR) and ligands' conformational preferences. Recently, advancements permitted determination of crystal structures for each of the opioid receptors in their antagonist-bound states [1-5]. These structures, combined with computational approaches, permit examination of how opioid ligands may bind to opioid receptors at the atomic level, knowledge that would facilitate the design and development of opioid receptor modulators with greater therapeutic potential.

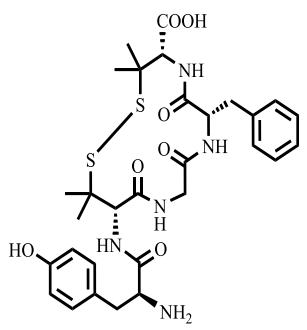

1

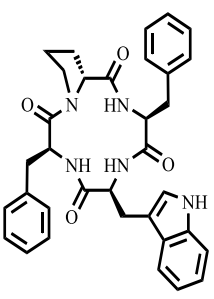

Fig. 1. Structures of DPDPE and CJ-15,208.

$\left[\mathrm{D}-\mathrm{Pen}^{2}, \mathrm{D}-\mathrm{Pen}^{5}\right.$ ]enkephalin (DPDPE, 1) (Figure 1) is a selective cyclic peptide agonist at the $\delta$ opioid receptor. The SAR and conformational preferences of DPDPE and its analogs were the subject of prior investigation [6-9]. These studies showed that the stereochemistry of the third amino acid has a profound effect on the structure and $\delta$ opioid receptor affinity of compounds in the series. This SAR makes DPDPE and its analogs particularly amenable to docking studies, which may help elucidate the active conformation of compounds possessing this scaffold.

The macrocyclic tetrapeptide CJ-15,208 (2) and its analogs also have a constrained cyclic structure and bind to opioid receptors [10-12] even though they lack the canonical opioid pharmacophore. While this unusual structure confers many desirable drug-like properties - including oral bioavailability and blood-brain barrier permeability [13-15] - it makes docking studies and rational design of CJ-15,208 analogs particularly challenging.

Herein we utilize docking studies to explore likely binding modes of DPDPE and its analogs, information that can then be used to predict possible binding modes of other opioid ligands, including macrocyclic tetrapeptides such as CJ-15,208.

\section{Results and Discussion}

Docking studies with DPDPE and its analogs were performed in four steps. First, a pharmacophore was generated using the atomic coordinates of the phenol $\left(\mathrm{Dmt}^{1}{ }^{1}\right.$, where $\mathrm{Dmt}=(S)-2^{\prime}, 6^{\prime}$ dimethyltyrosine), $N$-terminal amine, and phenyl $\left(\mathrm{Phe}^{3}\right)$ moieties of DIPP-NH (Dmt-Tic-Phe-Phe$\mathrm{NH}_{2}$, where Tic $=(S)$-1,2,3,4-tetrahydro-3-isoquinolinecarboxylic acid) present in the published $\delta$ opioid receptor crystal structure [3]. Then, using the coordinates from their crystal structures [6,7], DPDPE, $\left[\mathrm{L}-\mathrm{Ala}^{3}\right] \mathrm{DPDPE}$, and [D-Ala $\left.{ }^{3}\right] \mathrm{DPDPE}$ were subjected to a conformational search to generate a library of conformers for each compound. These conformer libraries underwent virtual screening for binding to a $\delta$ opioid receptor model, using the pharmacophore to place conformers into the pocket of the receptor. Finally, the top pose(s) were minimized to obtain final docked pose(s) and docking score(s) were measured.

Using this methodology, only [L-Ala $\left.{ }^{3}\right]$ DPDPE was capable of aligning all of its essential elements - its phenol $\left(\mathrm{Tyr}^{1}\right), N$-terminal amine, and phenyl $\left(\mathrm{Phe}^{4}\right)$ moieties - with those of DIPP-NH 2. Although the phenol and amine moieties of DPDPE and [D-Ala ${ }^{3}$ DPDPE overlay with those of DIPP-NH $\mathrm{N}_{2}$, their phenyl groups did not overlap with the important phenyl group of DIPP- $\mathrm{NH}_{2}$ (Figure 2a). Thus, we propose that the structure of $\left[\mathrm{L}-\mathrm{Ala}^{3}\right] \mathrm{DPDPE}$ best resembles the likely bioactive conformation of DPDPE and its analogs, although it is the preferred conformation for only [L-Ala ${ }^{3}$ DPDPE, and not DPDPE or $\left[\mathrm{D}-\mathrm{Ala}^{3}\right] \mathrm{DPDPE}$, in aqueous solution. 

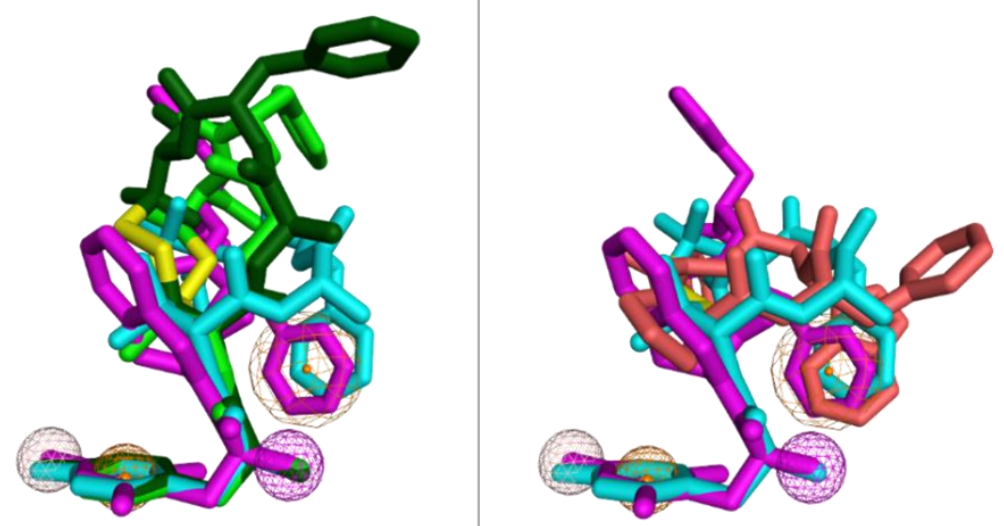

Fig. 2. a) Overlay of DPDPE (light green), [D-Ala ${ }^{3}$ DPDPE (dark green), and [L-Ala $\left.{ }^{3}\right] D P D P E$ (cyan) with DIPP-NH $\mathrm{NH}_{2}$ (magenta) from the crystal structure of the $\delta$ opioid receptor. Only [L-Ala $\left.{ }^{3}\right] D P D P E$ was capable of overlapping all its pharmacophore elements with those in DIPP-NH $\mathrm{N}_{2}$ (spheres) in the docking studies. b) Overlay of [L-Ala $\left.{ }^{3}\right] D P D P E$ (cyan), DIPP-NH $\mathrm{N}_{2}$ (magenta), and CJ-15,208 (rose). In this pose, CJ-15,208 achieves overlap with the essential aromatic residue of DIPP-NH $\mathrm{H}_{2}$ and the backbone of $\left[L-A l a^{3}\right] D P D P E$.

Next, docking studies were performed with CJ-15,208. Similar to before, a library of conformers was generated and then docked - using either the phenol or phenyl element from the prior pharmacophore to guide ligand placement - into a $\kappa$ opioid receptor model. Unfortunately, this process yielded poses that had significant steric clashes between the peptide and the receptor. Therefore, CJ-15,208 was subsequently placed into the $\kappa$ receptor model manually.

Following manual placement, the essential Trp ${ }^{4}$ aromatic group of CJ-15,208 overlapped with the phenyl group of DIPP- $\mathrm{NH}_{2}$, and the cyclic backbone of CJ-15,208 achieved significant overlap with the cyclic portion of [L-Ala ${ }^{3}$ DPDPE in its proposed bioactive conformation at the $\delta$ opioid receptor (Figure 2b). While other poses are plausible, the degree of overlap with this pose is encouraging. We are currently using this information to design and synthesize novel CJ-15,208 analogs.

\section{Acknowledgments}

This research was supported by R01 DA018832 (National Institute on Drug Abuse) and the University of Florida. Special thanks to the American Peptide Society for an APS Travel Grant for MJF.

\section{References}

1. Wu, H., et al. Nature 485, 327-332 (2012), http://dx.doi.org/10.1038/nature10939

2. Granier, S., et al. Nature 485, 400-404 (2012), http://dx.doi.org/10.1038/nature11111

3. Fenalti, G., et al. Nat. Struct. Mol. Biol. 22, $265-268$ (2015), http://dx.doi.org/10.1038/nsmb.2965

4. Fenalti, G., et al. Nature 506, 191-196 (2014), http://dx.doi.org/10.1038/nature12944

5. Manglik, A., et al. Nature 485, 321-326 (2012), http://dx.doi.org/10.1038/nature10954

6. Flippen-Anderson, J.L., et al. J. Am. Chem. Soc. 116, 7523-7531 (1994),

http://dx.doi.org/10.1021/ja00096a008

7. Collins, N., et al. J. Am. Chem. Soc. 118, 2143-2152 (1996), http://dx.doi.org/10.1021/ja9531081

8. Haaseth, R.C., et al. J. Med. Chem. 37, 1572-1577 (1994), http://dx.doi.org/10.1021/jm00037a007

9. Haaseth, R.C., et al. Int. J. Pept. Protein Res. 36, 139-146 (1990), http://dx.doi.org/10.1111/j.13993011.1990.tb00957.x

10. Saito, T., et al. J. Antibiot. 55, 847-854 (2002), http://doi.org/10.7164/antibiotics.55.847

11. Aldrich, J.V., et al. ChemMedChem 6, 1739-1745 (2011), http://dx.doi.org/10.1002/cmdc.201100113

12. Aldrich, J.V., et al. Br. J. Pharmacol. 171, 3212-3222 (2014), http://doi.org/10.1111/bph.12664

13. Aldrich, J.V., et al. J. Nat. Prod. 76, 433-438 (2013), http://dx.doi.org/10.1021/np300697k

14. Ross, N.C., et al. Br. J. Pharmacol. 165, 1097-1108 (2012), http://dx.doi.org/10.1111/j.1476-

5381.2011.01544.X

15. Eans, S.O., et al. Br. J. Pharmacol. 169, 426-436 (2013), http://dx.doi.org/10.1111/bph.12132 